Article

\title{
Heuristic vs. Meta-Heuristic Optimal Energy Design for an Office Building
}

\author{
Won-Jun Suh and Cheol-Soo Park* \\ School of Civil, Architectural Engineering and Landscape Architecture, Sungkyunkwan University, Suwon, \\ Gyeonggi 440-746, Korea; qqq000feel@skku.edu \\ * Correspondence: cheolspark@skku.ac.kr; Tel.: +82-31-290-7567
}

Academic Editor: Vladimir Strezov

Received: 29 December 2016; Accepted: 23 March 2017; Published: 27 March 2017

\begin{abstract}
In this paper, an application of heuristic vs. meta-heuristic approaches to the design of an office building is presented. The building was first optimized by a heuristic approach based on the designers' expertise, prior experiences and intuitions with the use of a whole building simulation tool, EnergyPlus. Then, a meta-heuristic approach was completed in MATLAB platform where EnergyPlus and Genetic Algorithm (GA) were coupled. M-script files were developed to automate execution of EnergyPlus simulation runs (reading output files and overwriting input files of EnergyPlus) in integration to GA. Based on a comparison between the heuristic and the meta-heuristic approach, it is shown that GA performs much better in finding a global optimum even under a constrained search space than the heuristic approach. The heuristic approach has advantages, such as reflection of a design context in decision-making and fast communication between stakeholders.
\end{abstract}

Keywords: heuristics; meta-heuristics; energyplus; genetic algorithm; building energy

\section{Introduction}

Due to the depletion of energy resources and global warming, it becomes important to achieve energy efficient building design. For this purpose, building energy simulation tools, e.g., EnergyPlus, IES-VE, etc., have been widely used for the building design process. Building designers rely on simulation tools in order to quantify the impact of design variables (e.g., insulation thickness, types of windows) on building energy consumption [1]. In the design process, simulation experts are invited to the design team for their intuitions and expertise, high-fidelity simulation runs, performance analysis, and rational decision making.

One of the most popular optimal design approaches employed in the aforementioned integrated design process is a heuristic approach. The heuristic approach is advantageous in that it can quickly find a good-enough solution with educated guesses, intuition, expertise, prior experience, etc. [2]. However, with the heuristic approach, it is hard to investigate an entire vast option space because it depends on a manual iterative process [3]. In other words, it is difficult to tell how optimal the good-enough solution is, which was determined by the heuristic approach [4].

In contrast to the heuristic approach, a meta-heuristic approach employs a computational method that iteratively improves a candidate solution with regard to a given measure of quality or an objective function. It can search for an optimal design solution within a vast option space.

In this study, two approaches (heuristic vs. meta-heuristic) were cross-compared for the optimal energy design of a post office building. It is generally true that the meta-heuristic approach, which uses the computer's resource, is superior to the heuristic approach that relies on the human brain's educated guess (expertise, experience, and intuition). Most of the recent optimal energy design studies have been focused on a comparison among meta-heuristic techniques or the application and practical use of optimization techniques [5-14]. Evins [14] and Attia et al. [15] summarized advanced issues, 
such as combination of optimization and simulation, optimization algorithms, tools for simulation and optimization, integration of optimization with design process, optimization shortcomings, etc.

Compared to the previous studies [5-15], this study was conducted in order to investigate why and how much better the meta-heuristic optimal design of a post office building is, than the heuristic optimal design. This paper is not intended to report a comprehensive optimal energy design case using an advanced optimization algorithm, e.g., stochastic multi-criterion optimization [16]. Rather, this paper reports an application of the heuristic and the meta-heuristic optimal energy design to a real design process. Simulation specialists became involved in this design process at a final design stage and architectural design variables were strongly constrained. Under this design context, this paper reports a comparison between the heuristic and the meta-heuristic approach.

For the heuristic optimal design of the given building, a team consisting of architectural designers and simulation specialists worked together for several weeks. The simulation specialists manually conducted iterative runs of EnergyPlus to optimize their design. Next, for the meta-heuristic approach, the simulation specialists integrated EnergyPlus-one of the whole building energy simulation tools-to an evolutionary algorithm, or Genetic Algorithm (GA). In the following sections, two approaches will be explained and cross-compared.

\section{Case Study}

The building is a three-story post office building with one underground floor, with a total floor area of about $978 \mathrm{~m}^{2}$. The building is located at Sejong City in South Korea $\left(36.48^{\circ} \mathrm{N}, 127.25^{\circ} \mathrm{E}\right)$, and the weather data of Daejeon city was used. The distance between Sejong City and Daejeon city is about $28 \mathrm{~km}$.

The shape of the building is nearly rectangular and it faces northeast (rotated 34 degrees clockwise from north). This northeast wall is the only wall that contains windows. $250 \mathrm{~mm}$-thick expanded polystyrene board (EPS) is applied as insulation of the aboveground external walls, and $250 \mathrm{~mm}$-thick extruded polystyrene board (XPS) is applied for the underground external walls. The building's roof has $300 \mathrm{~mm}$ EPS board. Each room in the building has a Fan Coil Unit (FCU) or packaged air conditioner, and those terminal units use Ground Source Heat Pumps (GSHP). Each room's ventilation is served by an Energy Recovery Ventilator (ERV). The building's plan and EnergyPlus model is shown in Figure 1. The thermal zoning of each floor corresponds to each architectural space (Figure 1a-d).

Since the building design process was close to the end of the design development stage, most of the architectural, mechanical, and electrical design variables were already determined. Most input variables for the EnergyPlus simulation were given by the design team, such as the density and schedule of lights, occupants, equipment, building operation (set-point temperature and relative humidity level in heating, cooling and intermediate seasons), ventilation rate, the angle and schedule of blind slats, etc. (Table 1). For example, it was determined by the design team that the blind slats angle would be maintained at 45 degrees from June to September, and the blinds to be drawn up in other periods. Thus, dynamic optimal control of blinds was not included in this study. 


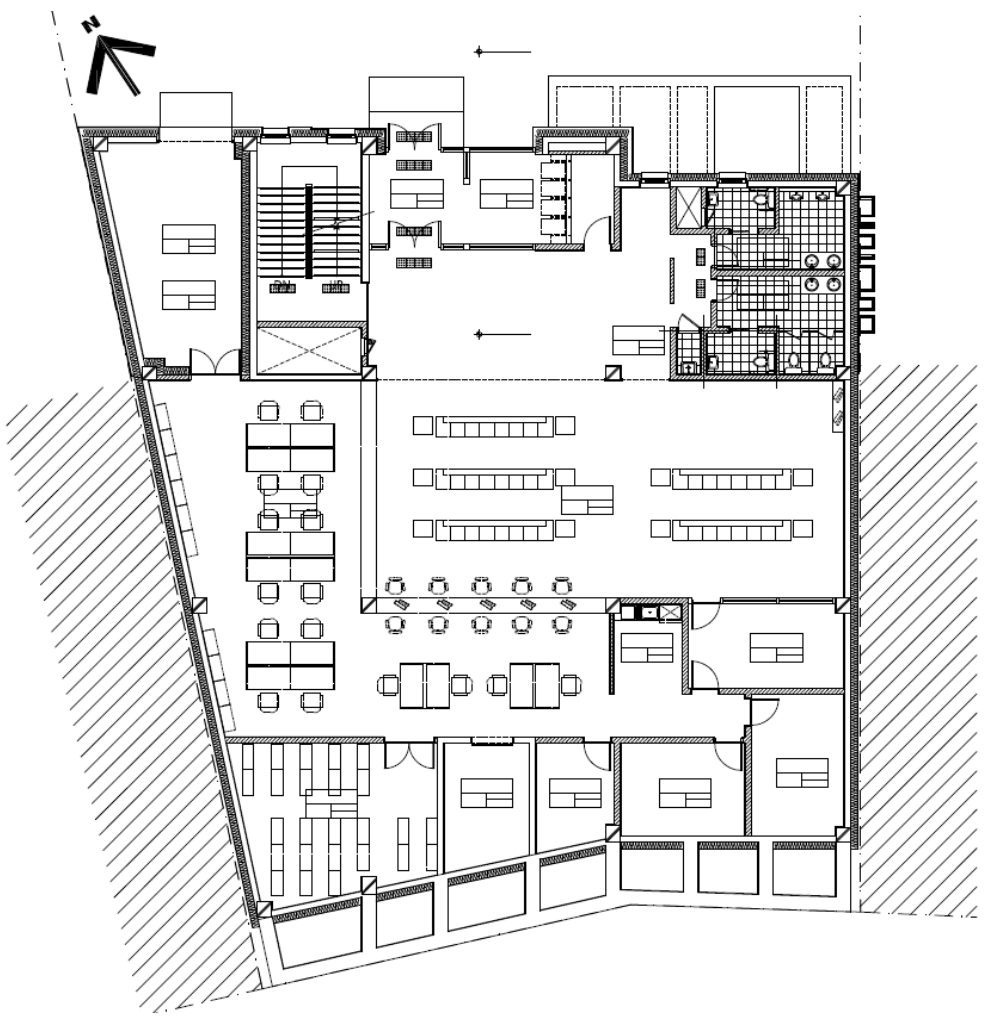

(a)

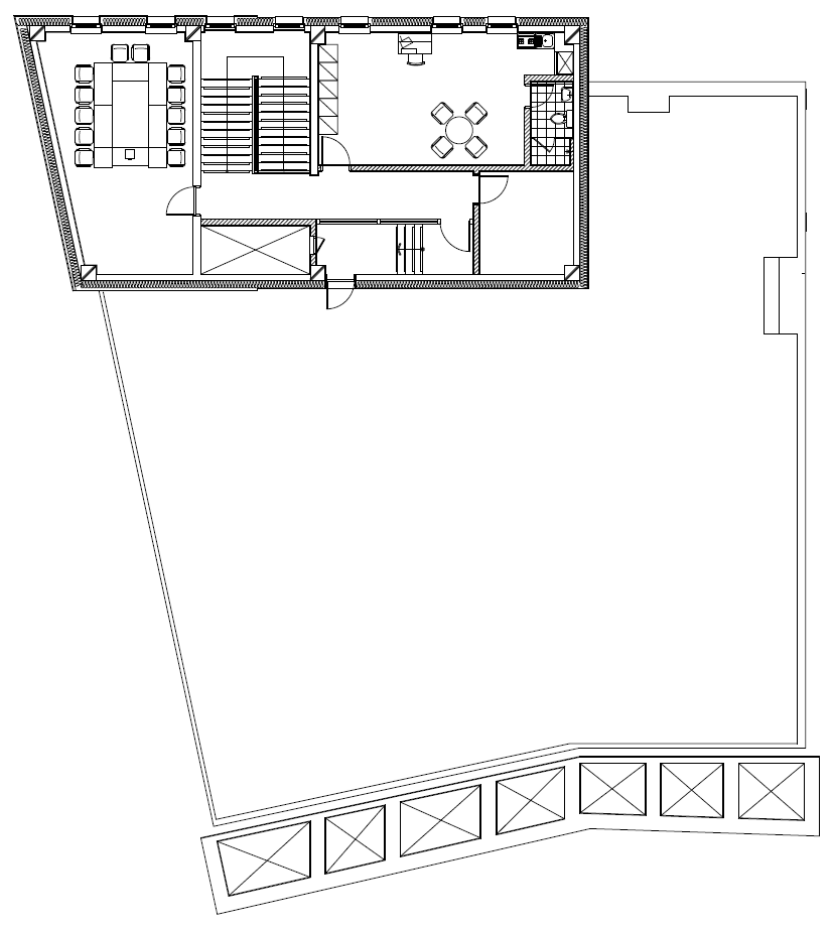

(b)

Figure 1. Cont. 


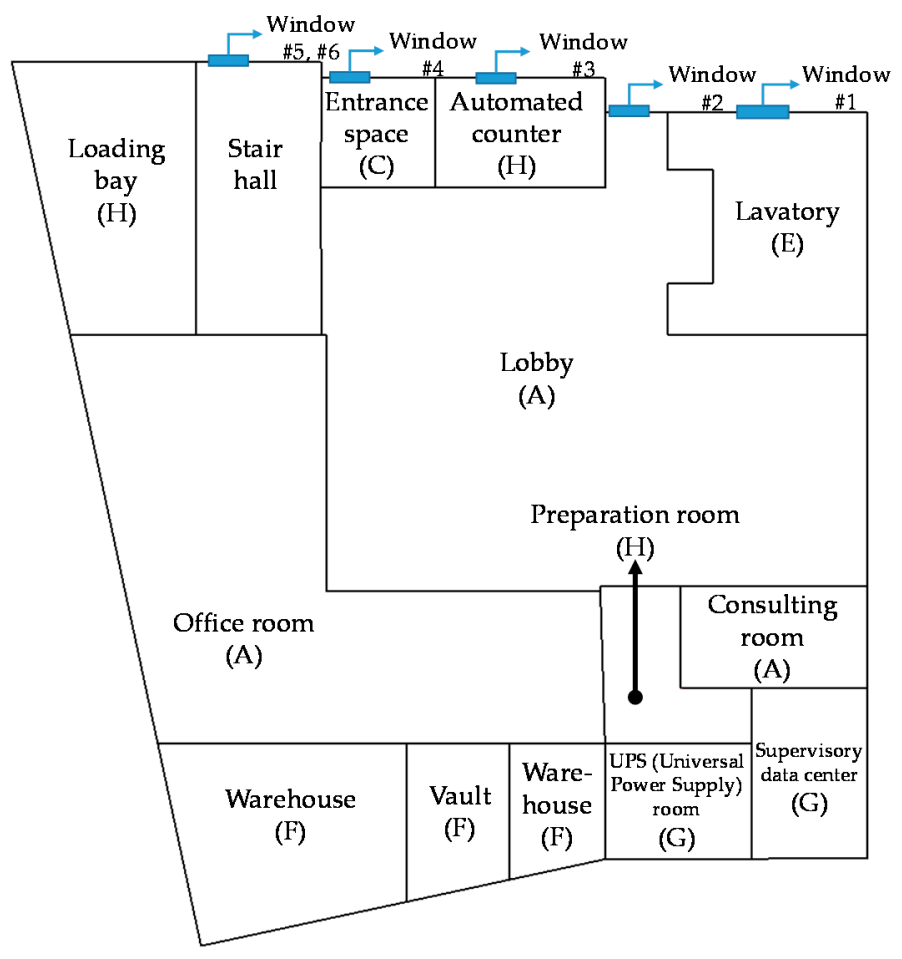

(c)

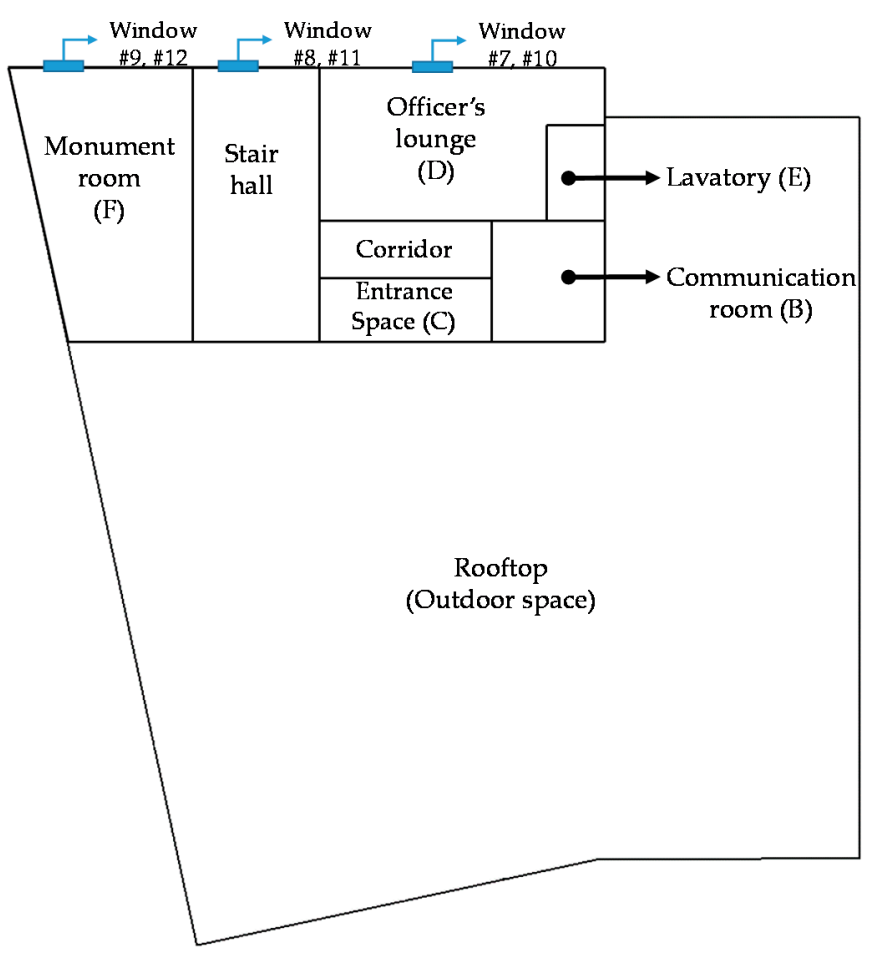

(d)

Figure 1. Cont. 


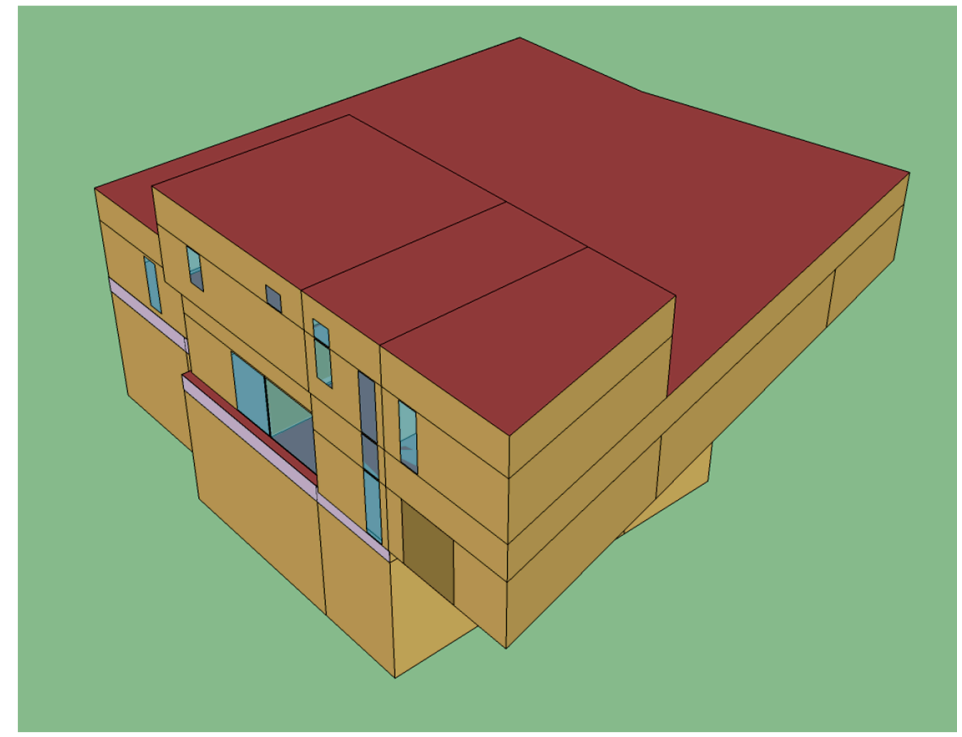

(e)

Figure 1. Plan and EnergyPlus model of the building (for room category remarked as A-H in Figure 1c,d, please refer to Table 1). (a) Plan (1st floor); (b) Plan (2nd floor); (c) Thermal zoning and location of windows (1st floor); (d) Thermal zoning and location of windows (2nd floor); and (e) EnergyPlus model.

Table 1. Input variables given by the design team.

\begin{tabular}{cccccc}
\hline $\begin{array}{c}\text { Room } \\
\text { Category * }\end{array}$ & $\begin{array}{c}\text { Operation } \\
\text { Time }\end{array}$ & $\begin{array}{c}\text { Minimum Outdoor } \\
\text { Air }(\mathbf{A C H})\end{array}$ & $\begin{array}{c}\text { Internal Equipment } \\
\mathbf{( \mathbf { W } / \mathbf { m } ^ { 2 } )}\end{array}$ & $\begin{array}{c}\text { Heating } \\
\text { Setpoint ('C) }\end{array}$ & $\begin{array}{c}\text { Cooling } \\
\text { Setpoint ('C) }\end{array}$ \\
\hline A & $09-18$ & 0.7 & 12 & 20 & 26 \\
B & $00-24$ & 0.4 & 30 & 22 & 26 \\
C & $09-18$ & 1.0 & 3.1 & 20 & 26 \\
D & $09-18$ & 1.25 & 10 & 20 & 26 \\
E & $09-18$ & 0.7 & 3.1 & 20 & 26 \\
F & $09-18$ & 0.4 & 25 & 20 & 26 \\
G & $00-24$ & 0.4 & 10 & 22 & 26 \\
H & $09-18$ & 1.25 & & 22 & 26 \\
\hline
\end{tabular}

* A $\left(332.0 \mathrm{~m}^{2}\right)$ : Lobby, office room, consulting room/B $\left(16.3 \mathrm{~m}^{2}\right)$ : communication room $/ \mathrm{C}\left(22.9 \mathrm{~m}^{2}\right)$ : entrance space/D $\left(37.3 \mathrm{~m}^{2}\right)$ : officer's lounge/E $\left(41.2 \mathrm{~m}^{2}\right)$ : lavatory $/ \mathrm{F}\left(115.3 \mathrm{~m}^{2}\right)$ : vault, warehouse, monument room/G $\left(18.9 \mathrm{~m}^{2}\right)$ : supervisory data center $/ \mathrm{H}\left(74.5 \mathrm{~m}^{2}\right)$ : automated counter, preparation room, loading bay. The location of each room category is shown in Figure 1c,d.

Under the aforementioned design context, the list of the design variables that simulation specialists could suggest to the design team was limited as follows: the insulation thickness of building envelopes (walls in B1 [the 1st floor below ground], 1F [the 1st floor above ground]-2F [the 2nd floor above ground], roof), the location of blinds (exterior vs. interior), application of LED lights, and a glazing type. Please note that there is no insulation applied to the slab of the underground floor because B1 floor accommodates only unconditioned zones, such as mechanical rooms and a water tank room. With regard to the glazing type, the design team specified the U-value of windows, not mentioning the glazing type. The design variables of the original design are shown in Table 2.

The time step used for the EnergyPlus simulation was 10 minutes. The simulation result with regard to the original base-case design (hereafter referred to as Case \#0) is as follows: annual total energy usage is 11,723 kWh (heating: $1378 \mathrm{kWh}$, cooling: 10,345 kWh). 
Table 2. Changeable design variables of the original design (Case \#0).

\begin{tabular}{llc}
\hline \multicolumn{1}{c}{ Design Variables } & \multicolumn{1}{c}{ Value of the Original Design } \\
\hline & Walls in $\mathrm{B} 1$ & $250 \mathrm{~mm}\left(0.117 \mathrm{~W} / \mathrm{m}^{2} \mathrm{~K}\right)$ \\
Insulation thickness and U-values of walls / roof & Walls in $1 \mathrm{~F}-2 \mathrm{~F}$ & $250 \mathrm{~mm}\left(0.118 \mathrm{~W} / \mathrm{m}^{2} \mathrm{~K}\right)$ \\
& Roof & $300 \mathrm{~mm}\left(0.100 \mathrm{~W} / \mathrm{m}^{2} \mathrm{~K}\right)$ \\
\hline Blinds & not installed \\
LED lights & not installed \\
U-value of glazing & $0.91 \mathrm{~W} / \mathrm{m}^{2} \mathrm{~K}$ (glazing type is not specified) \\
\hline
\end{tabular}

\section{Three Optimization Cases}

\subsection{Case \#1: Heuristic Approach}

The heuristic approach was applied first. This approach finds an optimal solution with the expertise, experience, and intuition of designers and specialists. In general, the building design stakeholders (e.g., architectural designers, MEP engineers, energy consultants, EnergyPlus simulationists, etc.) suggest probable design variables at each design iteration. Then, the proposed design variables are tested with the use of the EnergyPlus simulation run. If energy-saving of the proposed design variables is confirmed, then an economic analysis is conducted and the proposed design variables are adopted if they are economically advantageous.

This heuristic design process is an iterative as well as collaborative design development process until the building design stakeholders become satisfactory with their design outcome. The building in this study is relatively small and thus the design-feedback process (e.g., modeling, simulation, analysis) of any proposed design was quickly conducted. As a result, the design variables decided by the heuristic approach are shown in Table 3, hereafter referred to as Case \#1.

The insulation thickness was determined to be same as that of the original design (Table 2), because the building design stakeholders in this study-consisting of the architectural design team and simulation specialists-regarded the insulation of the original design as sufficiently thick $(250 \mathrm{~mm}$ or $300 \mathrm{~mm}$ ) (Tables 2 and 3). With regard to the location of blinds (exterior vs. interior), the design stakeholders assumed that the exterior blinds would be more beneficial, because they can block solar radiation flowing into the building more effectively than interior blinds.

Because LED lights are still expensive, as compared to fluorescent lamps, it was suggested that the LED lights should be installed in the two rooms (the office room in Figure $1 \mathrm{c}$ and the monument room in Figure 1d) which require long burning hours per day. The power density of LED lights is $8.9 \mathrm{~W} / \mathrm{m}^{2}$ and $13.4 \mathrm{~W} / \mathrm{m}^{2}$, respectively, and its operation schedule is the same as the room operation schedule as shown in Table 1.

Finally, triple low-e glazing (U-value of $0.774 \mathrm{~W} / \mathrm{m}^{2} \mathrm{~K}$, g-value of 0.433 ) was selected, since it is one of the most feasible choices in terms of the U-value, g-value, and market price.

Please note that if the building was large or complex, the simulation run-time may easily exceed $10 \mathrm{~h}$, not to mention demanding time and effort for selecting probable design variables, updating a simulation input file modeling, and analyzing a simulation result. 
Table 3. Design variables determined by the heuristic approach (Case \#1).

\begin{tabular}{|c|c|c|}
\hline Design Variables & & Value \\
\hline $\begin{array}{l}\text { Insulation thickness and } \\
\text { U-values of walls/roof }\end{array}$ & $\begin{array}{c}\text { Walls in B1 } \\
\text { Walls in 1F-2F } \\
\text { Roof }\end{array}$ & $\begin{array}{l}250 \mathrm{~mm}\left(0.117 \mathrm{~W} / \mathrm{m}^{2} \mathrm{~K}\right) \\
250 \mathrm{~mm}\left(0.118 \mathrm{~W} / \mathrm{m}^{2} \mathrm{~K}\right) \\
300 \mathrm{~mm}\left(0.100 \mathrm{~W} / \mathrm{m}^{2} \mathrm{~K}\right)\end{array}$ \\
\hline Blinds & $\begin{array}{l}\text { External blinds to be installed to all } \\
\text { windows }\end{array}$ & $\begin{array}{l}\text { beam } / \text { diffuse } / \text { visible transmittance }=0.0 \\
\text { front } / \text { back beam } / \text { diffuse } / \text { visible } \\
\text { reflectance }=0.5 \\
\text { front } / \text { back infrared emissivity }=0.9 \\
\text { slat conductivity }=0.9(\mathrm{~W} / \mathrm{mK})\end{array}$ \\
\hline LED Lights & \multicolumn{2}{|c|}{ LED lights to be installed in two rooms requiring long burning hours per day } \\
\hline Glazing & \multicolumn{2}{|c|}{$\begin{array}{l}\text { all glazing: triple low-e glazing (U-value: } 0.774 \mathrm{~W} / \mathrm{m}^{2} \mathrm{~K}, \mathrm{~g}=0.433, e=0.1 \text { on surfaces } \\
2,4)\end{array}$} \\
\hline
\end{tabular}

\subsection{Case \#2: Meta-Heuristic Approach by Genetic Algorithm (GA) Applied to a Constrained Search Space}

GA is a robust optimization method, especially when an optimization problem is not smooth and unimodal, not well understood, or the fitness function is noisy $[17,18]$. GA was selected in this study because our optimal design problem cannot be solved with gradient-based optimization. The integration of GA to EnergyPlus will be elaborated in Section 4.

As mentioned in Section 2, most of the architectural, mechanical, and electrical design variables were already fixed and the changeable design variables are limited (Tables 2 and 3 ). The aforementioned changeable design variables were discretized in order to be used in GA, as shown in Table 4.

The minimum values of insulation thickness were set to South Korean building codes. The maximum values of insulation thickness were assumed to be the values of insulation thickness of the original design, plus $100 \mathrm{~mm}$. Then, the insulation thickness is discretized with $10 \mathrm{~mm}$ increment and the genetic algorithm finds the optimal insulation thickness at each floor. For blinds, there are three alternatives: no blinds, internal blinds, and external blinds. Each of the twelve windows in the building was assumed to have a respective option. LED lights were assumed to either be installed or not, in the fifteen rooms in the building. With regard to the glazing type, three options were made: low-e triple glazing, low-e double glazing, and clear double glazing. Each of the twelve windows was assumed to have either one out of three glazing options. In total, the possible number of design alternatives becomes about $6.3 \times 10^{21}\left(=29^{3} \times 28 \times 3^{12} \times 2^{15} \times 3^{12}\right)$ (Table 4). The objective function in our study is defined as the sum of annual heating energy consumption and annual cooling energy consumption.

Table 4. Design variables and constraints for Genetic Algorithm (GA).

\begin{tabular}{|c|c|c|c|c|}
\hline \multicolumn{2}{|c|}{ Design Variables } & \multirow{2}{*}{$\begin{array}{r}\text { Range } \\
70-350\end{array}$} & \multirow{3}{*}{$\begin{array}{r}\text { Description } \\
\text { Increment of } 10 \mathrm{~mm} \text { interval }\end{array}$} & \multirow{2}{*}{$\begin{array}{c}\text { The Number of } \\
\text { Design Options } \\
29^{3}\end{array}$} \\
\hline $\begin{array}{l}\text { Insulation } \\
\text { thickness }(\mathrm{mm})\end{array}$ & $\begin{array}{l}\text { Walls in B1, } \\
\text { 1F-2F }\end{array}$ & & & \\
\hline & Roof & $135-400$ & & 28 \\
\hline \multicolumn{2}{|c|}{ Blinds } & $0-2$ & $\begin{array}{l}\text { 0: No blinds } \\
\text { 1: Internal blinds } \\
\text { 2: External blinds }\end{array}$ & $3^{12}$ \\
\hline \multicolumn{2}{|c|}{ LED lights } & 0,1 & $\begin{array}{l}\text { 0: Not installed } \\
\text { 1: Installed }\end{array}$ & $2^{15}$ \\
\hline \multicolumn{2}{|c|}{ Glazing } & $0-2$ & $\begin{array}{l}\text { 0: Triple low-e glazing }\left(\mathrm{U}=0.774 \mathrm{~W} / \mathrm{m}^{2} \mathrm{~K},\right. \\
\mathrm{g}=0.433, e=0.1 \text { on surfaces } 2,4) \\
\text { 1: Double Low-e glazing }(\mathrm{U}=1.45 \\
\left.\mathrm{W} / \mathrm{m}^{2} \mathrm{~K}, \mathrm{~g}=0.571, e=0.1 \text { on surface } 2\right) \\
\text { 2: Clear double glazing }\left(\mathrm{U}=2.52 \mathrm{~W} / \mathrm{m}^{2} \mathrm{~K},\right. \\
\mathrm{g}=0.719)\end{array}$ & $3^{12}$ \\
\hline
\end{tabular}


3.3. Case \#3: Meta-Heuristic Approach by Genetic Algorithm (GA) Applied to a Less Constrained Search Space (One More Option of a Design Variable)

If GA optimization had been applied at an earlier design stage, more varied design variables could have been optimized. To verify this hypothesis, the authors assumed that the window-wall ratio (WWR) could be changeable, and performed an additional optimization. WWR is defined as the ratio of each window's area to the area of the wall where each window is installed. In this extended optimization, the following assumptions were made:

- The list of design variables to be optimized is the same as in Case \#2. In addition, it is assumed that the window-wall ratio of each window can be optimized ranging from $1 \%$ to $99 \%$.

- The number of windows remains the same as that of the original design (Figure 1).

- The location of each window remains the same as that of the original design (Figure 1).

The number of possible design combinations becomes about $5.6 \times 10^{45}\left(=29^{3} \times 28 \times 3^{12} \times 2^{15} \times\right.$ $3^{12} \times 99^{12}$ ), where 99 means $1 \%$ increment of window-wall ratio. The objective function is the same as the one described in Section 3.2.

\section{Implementation of GA Integrated to EnergyPlus}

In GA, a population of strings-which encode candidate solutions to an optimization problem-evolves toward better solutions. There are a certain number of individuals in each population, and each individual is comprised of binary strings that reflect the design variables in the real world. The typical number of individuals in each population range from 30 to 200 [19]. In this study, the numbers of generations and individuals were set to 80 and 30, respectively.

The GA is progressed as follows: first, the initial population is generated. After the generation, the values of variables are randomly selected between minimum and maximum, and assigned to each individual as a form of binary numbers. Then, optimization is performed through the following five iterative processes.

- Fitness evaluation: evaluate each individual using the given objective function. The value of the function is the fitness of each individual.

- Selection: two randomly-selected individuals participate in the selection operation to reproduce offspring. The higher fitness, the more chance to be selected.

- Recombination: mixing of values occurs between selected individuals.

- Mutation: a probabilistic bit-wise mutation proceeds, in which a given gene value is flipped from 0 to 1 , or vice versa. A larger space is explored with this operation.

- Elitism: in this study, all other solutions except the top two solutions having the highest fitness were replaced. This guarantees that the search does not diverge from a solution having a higher objective function than that already found by the search.

GA operators (selection, recombination, mutation) are iteratively executed and improve each individual during the GA process (Figure 2). When choosing the GA methods and parameters (Table 5), the balance between the degree of global optimality and convergence speed must be taken into account [20-22]. In this study, the following methods and parameters were selected as tabulated in Table 5 [23].

Table 5. GA operators, methods and parameters.

\begin{tabular}{lll}
\multicolumn{1}{c}{$\begin{array}{c}\text { Genetic } \\
\text { Operator }\end{array}$} & \multicolumn{1}{c}{ Method } & \multicolumn{1}{c}{ Parameter } \\
\hline $\begin{array}{l}\text { Selection } \\
\text { Recombination }\end{array}$ & Tournament selection & - \\
Mutation & Uniform crossover & An average of $50 \%$ of the bits are swapped \\
\hline
\end{tabular}


The integration of GA to EnergyPlus was realized on MATLAB platform. In this study, every iteration of GA was executed by MATLAB script files written by the authors. EnergyPlus input files $\left({ }^{*}\right.$.idf) were automatically generated with updated new design variables. EnergyPlus output files were also automatically analyzed by MATLAB script files (Figure 2).

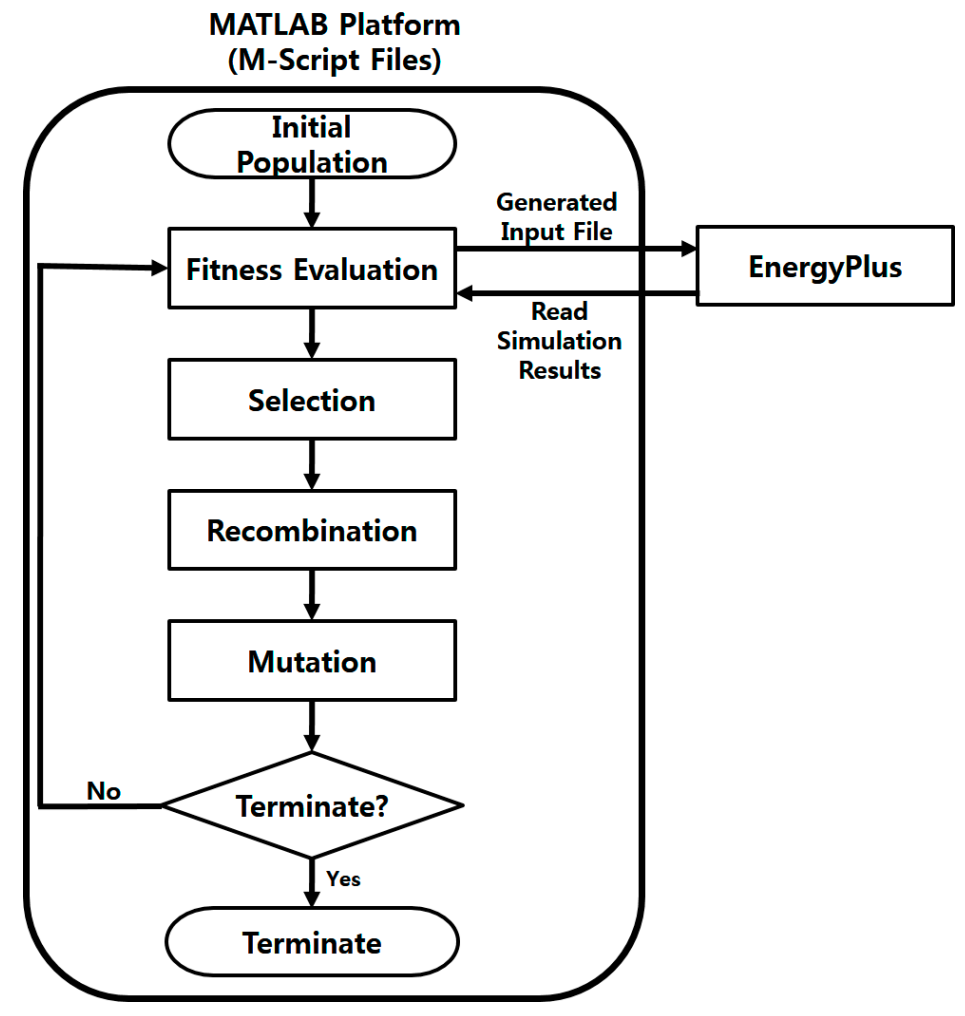

Figure 2. Flowchart of GA integrated to EnergyPlus.

\section{Results}

5.1. Case \#0 (Original Design), Case \#1 (Heuristic) vs. Case \#2 (Meta-Heuristic Approach Applied to a Constrained Search Space)

The building's heating and cooling energy as optimized by the heuristic (Case \#1) and the meta-heuristic approaches were compared to those of the original design (Case \#0) (Table 6, Figure 3). Of the original design's total energy consumption, $24 \%$ and $33 \%$ can be saved by the heuristic and the meta-heuristic approaches. Especially, there is no significant reduction in cooling energy between Case $\# 1$ and Case \#2. Compared to Case \#1, Case \#2 saved more energy by $9 \%$.

Table 6. Comparison of heating and cooling energy between three cases (Cases \#0, \#1, \#2).

\begin{tabular}{cccc}
\hline & Heating (kWh) & Cooling $\mathbf{( k W h )}$ & Total $(\mathbf{k W h})$ \\
\hline Case \#0 & $1378(100 \%)$ & $10,345(100 \%)$ & $11,723(100 \%)$ \\
Case \#1 & $1240(90 \%)$ & $7704(74 \%)$ & $8944(76 \%)$ \\
Case \#2 & $471(34 \%)$ & $7375(71 \%)$ & $7847(67 \%)$ \\
\hline
\end{tabular}

The numbers in parentheses refer to a relative percentage compared to Case \#0. 


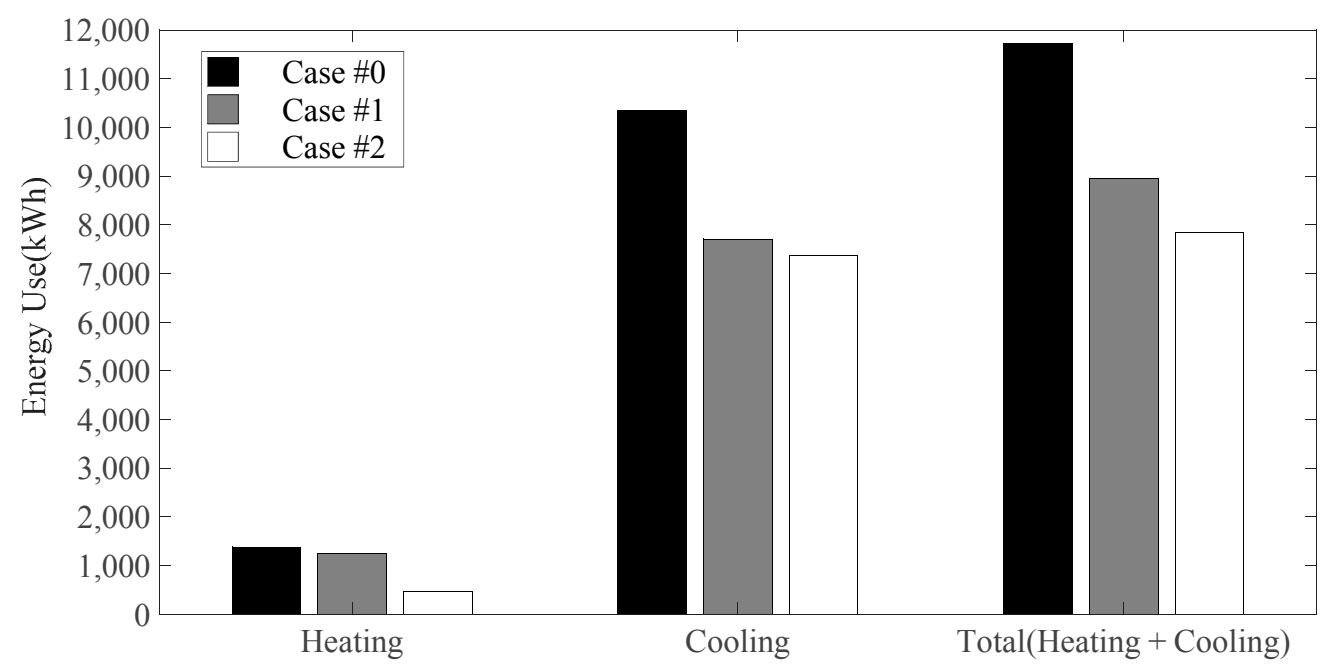

Figure 3. Comparison of annual heating and cooling energy between Cases \#0, \#1 and \#2.

The design variables determined by the heuristic and the meta-heuristic approaches are tabulated in Table 7. It is noteworthy that the insulation thicknesses of walls in each floor obtained from the meta-heuristic approach (GA) are different from each other (e.g., $130 \mathrm{~mm}$ in B1, $310 \mathrm{~mm}$ in 1F, $310 \mathrm{~mm}$ in $2 \mathrm{~F})$. In addition, the insulation thicknesses of each floor were not close to its minimum $(70 \mathrm{~mm}$ for walls, $135 \mathrm{~mm}$ for roof) or maximum ( $350 \mathrm{~mm}$ for walls, $400 \mathrm{~mm}$ for roof) value (Table 4). It was speculated that GA found a converging optimal point between heat-gain and heat-loss during one year.

It was found by GA that external blinds are advantageous for the energy savings of the building, which is the same with the decision of Case \#1, determined by the intuition that external blinds would be effective in blocking solar radiation. It is found from GA that LED lights should be installed in all rooms due to its luminous efficacy. It is interesting that the glazing types of twelve windows obtained from GA are not identical. Surprisingly, three double low-e glazings are included in Case \#2 (Table 7). To verify this, the authors performed additional simulation runs, which will be described below.

Table 7. Comparison of design variables.

\begin{tabular}{|c|c|c|c|c|}
\hline \multirow{2}{*}{\multicolumn{2}{|c|}{ Design Variables }} & \multicolumn{3}{|c|}{ Value } \\
\hline & & $\begin{array}{l}\text { Original Design } \\
\text { (Case \#0) }\end{array}$ & Heuristic (Case \#1) & $\begin{array}{l}\text { Meta-Heuristic } \\
\quad \text { (Case \#2) }\end{array}$ \\
\hline \multirow{4}{*}{$\begin{array}{l}\text { Insulation } \\
\text { thickness (mm) }\end{array}$} & Walls in B1 & $250 \mathrm{~mm}$ & $250 \mathrm{~mm}$ & $130 \mathrm{~mm}$ \\
\hline & Walls in $1 \mathrm{~F}$ & $250 \mathrm{~mm}$ & $250 \mathrm{~mm}$ & $310 \mathrm{~mm}$ \\
\hline & Walls in $2 \mathrm{~F}$ & $250 \mathrm{~mm}$ & $250 \mathrm{~mm}$ & $230 \mathrm{~mm}$ \\
\hline & Roof & $300 \mathrm{~mm}$ & $300 \mathrm{~mm}$ & $385 \mathrm{~mm}$ \\
\hline \multicolumn{2}{|c|}{ Blinds } & Not installed & All external blinds & All external blinds \\
\hline \multicolumn{2}{|c|}{ LED lights } & Not installed & $\begin{array}{l}\text { Installed in two } \\
\text { rooms }\end{array}$ & Installed in all rooms \\
\hline \multirow{12}{*}{$\begin{array}{l}\text { Glazing in } \\
\text { room \# }\end{array}$} & 1 & \multirow{12}{*}{$\begin{array}{l}\text { Specified in terms of } \\
\text { the U-calue of } 0.91 \\
\qquad \mathrm{~W} / \mathrm{m}^{2} \mathrm{~K}\end{array}$} & \multirow{12}{*}{$\begin{array}{l}\text { Triple low-e glazing } \\
\text { for all twelve } \\
\text { windows }\end{array}$} & Double low-e glazing \\
\hline & 2 & & & Triple low-e glazing \\
\hline & 3 & & & Triple low-e glazing \\
\hline & 4 & & & Triple low-e glazing \\
\hline & 5 & & & Triple low-e glazing \\
\hline & 6 & & & Double low-e glazing \\
\hline & 7 & & & Triple low-e glazing \\
\hline & 8 & & & Triple low-e glazing \\
\hline & 9 & & & Double low-e glazing \\
\hline & 10 & & & Triple low-e glazing \\
\hline & 11 & & & Triple low-e glazing \\
\hline & 12 & & & Triple low-e glazing \\
\hline
\end{tabular}


To test the optimization result of Case \#2 (Table 7), the authors conducted three additional simulation runs by changing insulation thicknesses and glazing types as follows:

- Case \#2-1: minimum insulation thickness is applied to building envelopes (70 mm for walls in B1, $1 \mathrm{~F} \& 2 \mathrm{~F}, 135 \mathrm{~mm}$ for roof). All other design variables are identical to those of Case \#2.

- Case \#2-2: maximum insulation thickness is applied to building envelopes ( $350 \mathrm{~mm}$ for walls in B1, 1F \& 2F, $400 \mathrm{~mm}$ for roof). All other design variables are identical to those of Case \#2.

- Case \#2-3: triple low-e glazing is applied to all twelve windows. Please note that in Case \#2, double low-e glazing was applied to three windows (Table 7). All other design variables are identical to those of Case \#2.

In Case \#2-1 (minimum insulation), heating energy was increased by $490 \%$ and cooling energy was decreased by $6 \%$, compared to Case \#2. This might be caused by the far less insulation that was applied to Case \#2 (Table 8).

In Case \#2-2 (maximum insulation), both heating and cooling energy were increased by $28 \%$ and $1 \%$, respectively, as compared to Case \#2. It can be inferred that, in heating mode, the amount of solar radiation to be transferred into indoor space would be reduced, due to thick insulation. Vice versa, the heat generated from lights, people, and equipment can't be released to the outside due to thick insulation in cooling mode. In other words, maximum insulation is not always advantageous, and the optimal insulation thickness must be decided with the consideration of a building's dynamic thermal characteristics. However, it is difficult to find such optimal insulation thickness of the building envelopes with the heuristic approach, as can be inferred from Tables 7 and 8.

In Case \#2-3, heating energy was increased by $23 \%$ and cooling energy was decreased by $0.24 \%$, and total energy (heating + cooling) was increased by $1 \%$, as compared to Case \#2. The increase of heating energy might be caused by the difference in g-values between double low-e ( $g=0.571)$ vs. triple low-e glazing $(\mathrm{g}=0.433)$ (Table 4$)$. Triple low-e glazing allows far less penetrated solar radiation into the indoor space than double low-e, leading to the increase of heating energy, as well as the decrease of cooling energy (Table 8).

As observed from Cases \#2, \#2-1, \#2-2, and \#2-3, it is difficult to appropriately select optimal building envelopes with the heuristic approach. In contrast, the optimization achieved from the meta-heuristic approach of Case \#2 shows the strength of GA.

Table 8. Annual heating and cooling energy by changing the insulation thicknesses and glazing types of Case \#2.

\begin{tabular}{cccc}
\hline & Heating (kWh) & Cooling (kWh) & Total (kWh) \\
\hline Case \#2 & $471(100 \%)$ & $7375(100 \%)$ & $7847(100 \%)$ \\
Case \#2-1 & $2306(490 \%)$ & $6902(94 \%)$ & $9208(123 \%)$ \\
Case \#2-2 & $601(128 \%)$ & $7468(101 \%)$ & $8069(108 \%)$ \\
Case \#2-3 & $578(123 \%)$ & $7357(99.76 \%)$ & $7935(101 \%)$ \\
\hline
\end{tabular}

The numbers in parenthesis refer to a relative percentage compared to Case \#2.

\subsection{Case \#3 Meta-Heuristic Approach by Genetic Algorithm (GA) Applied to a Less Constrained Search Space}

Table 9 shows the comparison between Case \#2 and Case \#3. If we optimized the window-wall ratio, annual heating and cooling energy could be reduced up to $91 \%$.

It is noteworthy that each window determined by the meta-heuristic approach has different blinds, different glazing types, and different WWRs (Table 10). There is a significant decline in each window's WWR, and it can be inferred that the difference in energy use between Case \#2 and Case \#3 might be mostly caused by the reduced WWR. The window's WWRs of Case \#3 might not be realistic, and further design confirmation by the stakeholders might be required.

Case \#3 is more diverse in terms of location of blinds, glazing types, and WWR, than Case \#2. It is difficult to reverse-engineer the optimized result with regard to Case \#2 and Case \#3 (Table 10). It can 
be inferred that GA could find optimal design variables by its own evolutionary algorithm, indicating the pros and the strength of the meta-heuristic optimization, compared to heuristic decision-making based on expertise and intuition of experts.

Table 9. Comparison between Case \#2 and Case \#3.

\begin{tabular}{cccc}
\hline & Heating (kWh) & Cooling $\mathbf{( k W h )}$ & Total (kWh) \\
\hline Case \#2 & $471(100 \%)$ & $7375(100 \%)$ & $7847(100 \%)$ \\
Case \#3 & $419(89 \%)$ & $6723(92 \%)$ & $7142(91 \%)$ \\
\hline
\end{tabular}

The numbers in parentheses refer to a relative percentage compared to Case \#2.

Table 10. Comparison of optimized design variables for Cases 2 and 3.

\begin{tabular}{|c|c|c|c|c|c|}
\hline \multicolumn{2}{|c|}{ Design Variables } & \multicolumn{2}{|c|}{ Case \#2 } & \multicolumn{2}{|c|}{ Case \#3 } \\
\hline \multirow{4}{*}{$\begin{array}{l}\text { Insulation } \\
\text { thickness (mm) }\end{array}$} & Walls in B1 & \multicolumn{2}{|c|}{$130 \mathrm{~mm}$} & \multicolumn{2}{|c|}{$100 \mathrm{~mm}$} \\
\hline & Walls in $1 \mathrm{~F}$ & \multicolumn{2}{|c|}{$310 \mathrm{~mm}$} & \multicolumn{2}{|c|}{$330 \mathrm{~mm}$} \\
\hline & Walls in $2 \mathrm{~F}$ & \multicolumn{2}{|c|}{$230 \mathrm{~mm}$} & \multicolumn{2}{|c|}{$320 \mathrm{~mm}$} \\
\hline & Roof & \multicolumn{2}{|c|}{$385 \mathrm{~mm}$} & \multicolumn{2}{|c|}{$350 \mathrm{~mm}$} \\
\hline \multirow{12}{*}{$\begin{array}{l}\text { Location of } \\
\text { Blinds }\end{array}$} & 1 & \multirow{12}{*}{\multicolumn{2}{|c|}{ All external blinds }} & \multicolumn{2}{|c|}{ External blinds } \\
\hline & 2 & & & \multirow{2}{*}{\multicolumn{2}{|c|}{$\frac{\text { blinds not installed }}{\text { blinds not installed }}$}} \\
\hline & 3 & & & & \\
\hline & 4 & & & \multirow{2}{*}{\multicolumn{2}{|c|}{$\begin{array}{l}\text { External blinds } \\
\text { blinds not installed }\end{array}$}} \\
\hline & 5 & & & & \\
\hline & 6 & & & \multicolumn{2}{|c|}{ External blinds } \\
\hline & 7 & & & \multicolumn{2}{|c|}{ External blinds } \\
\hline & 8 & & & \multicolumn{2}{|c|}{ External blinds } \\
\hline & 9 & & & \multicolumn{2}{|c|}{ External blinds } \\
\hline & 10 & & & \multicolumn{2}{|c|}{ External blinds } \\
\hline & 11 & & & \multicolumn{2}{|c|}{ External blinds } \\
\hline & 12 & & & \multicolumn{2}{|c|}{ External blinds } \\
\hline \multicolumn{2}{|l|}{ LED lights } & Install & 11 rooms & Instal & 11 rooms \\
\hline & 1 & & $w-e$ & & w-e \\
\hline & 2 & & $w-e$ & & lear \\
\hline & 3 & & $w-e$ & & lear \\
\hline & 4 & & $w-e$ & & $\overline{w-e}$ \\
\hline & 5 & & w-e & & w-e \\
\hline & 6 & & $w-e$ & & $w-e$ \\
\hline Type of Glazıng & 7 & & $w-e$ & & w-e \\
\hline & 8 & & $w-e$ & & $w-e$ \\
\hline & 9 & & $w-e$ & & w-e \\
\hline & 10 & & $w-e$ & & lear \\
\hline & 11 & & $w-e$ & & $\frac{w-e}{w-e}$ \\
\hline & 12 & & w-e & & w-e \\
\hline & & WWR & Area $\left(\mathrm{m}^{2}\right)$ & WWR & Area $\left(\mathrm{m}^{2}\right)$ \\
\hline & 1 & $11 \%$ & 1.90 & $1 \%$ & 0.17 \\
\hline & 2 & $36 \%$ & 1.90 & $1 \%$ & 0.05 \\
\hline & 3 & $38 \%$ & 5.40 & $3 \%$ & 0.41 \\
\hline & 4 & $77 \%$ & 7.52 & $17 \%$ & 1.63 \\
\hline Window-Wall & 5 & $34 \%$ & 4.32 & $1 \%$ & 0.10 \\
\hline Ratio (WWR) and & 6 & $33 \%$ & 2.26 & $10 \%$ & 0.63 \\
\hline window area & 7 & $15 \%$ & 3.66 & $8 \%$ & 1.90 \\
\hline & 8 & $20 \%$ & 1.91 & $2 \%$ & 0.19 \\
\hline & 9 & $24 \%$ & 3.83 & $1 \%$ & 0.14 \\
\hline & 10 & $12 \%$ & 1.68 & $1 \%$ & 0.13 \\
\hline & 11 & $17 \%$ & 1.12 & $2 \%$ & 0.12 \\
\hline & 12 & $14 \%$ & 1.20 & $10 \%$ & 0.84 \\
\hline
\end{tabular}

To test the optimization result of Case \#3, the authors conducted two additional simulation runs, as follows:

- Case \#3-1: all blinds are located externally. All other design variables are identical to those of Case \#3 
- Case \#3-2: triple low-e glazing is applied to 12 windows. All other design variables are identical to those of Case \#3

The results are shown in Table 11. In Case \#3-1, heating energy was increased. It might be due to the external blinds, which can block solar radiation flowing into the building. Vice versa, there was a reduction in cooling energy, since it can effectively keep solar radiation from entering the building. In total, there was a total energy reduction of $0.1 \%$, equivalent to $7 \mathrm{kWh}$, compared to Case \#3 (Table 11).

Thus, it can be said that Case \#3 is a local optima. In general, GA is good enough to locate the global optima, or a local optima close to the global optima, even if the size of a solution space (the number of design alternatives) is very large [24]. GA usually converges toward a global optimal solution, but may fail to find the exact global optimal solution [1,25]. In Case \#3-2, the increase of heating energy and the decrease of cooling energy are due to the fact that triple low-e glazing reduces solar radiation flowing into the rooms, as compared to Case \#3 (Table 10).

Table 11. Annual heating and cooling energy by blinds and glazing types of Case \#3.

\begin{tabular}{cccc}
\hline & Heating (kWh) & Cooling $(\mathbf{k W h})$ & Total $(\mathbf{k W h})$ \\
\hline Case \#3 & $419(100 \%)$ & $6723(100 \%)$ & $7142(100 \%)$ \\
Case \#3-1 & $478(114 \%)$ & $6658(99 \%)$ & $7135(99.9 \%)$ \\
Case \#3-2 & $492(117 \%)$ & $6691(99.5 \%)$ & $7183(100.6 \%)$ \\
\hline
\end{tabular}

The numbers in parentheses refer to a relative percentage compared to Case \#3.

\section{Conclusions}

In this paper, the authors compared three optimization cases of an office building. The original design was updated with the three optimal design approaches: heuristic (Case \#1), meta-heuristic by GA in the constrained search space (Case \#2), and meta-heuristic by GA in the less constrained search space (Case \#3).

The integration of GA to EnergyPlus was realized on MATLAB platform. M-script files, written by the authors, could iteratively generate EnergyPlus input files, conduct EnergyPlus simulation, and analyze EnergyPlus output files in the GA process.

Since the optimization approaches were adopted at the end of the design development stage, a limited list of design variables were given (Table 2). However, $24 \%$ and $33 \%$ of the total energy of the original design can be saved by the heuristic (Case \#1) and the meta-heuristic approaches (Case \#2), respectively (Table 6). In the heuristic approach, construction cost with the LED lights was regarded to be too high, and accordingly it was determined that the LED lights should be installed in two rooms only.

It was found and tested that the meta-heuristic approach is far superior to the heuristic approach in searching for an optimal design (Tables 7-11). For instance, the meta-heuristic approach suggests that the insulation thickness of walls on each floor should be different (Table 7). The insulation thickness of walls and roof is neither the minimum nor the maximum value of the design variable. It is difficult to reverse-engineer why such values of the insulation thickness could enable the building to be more energy-efficient. It is the same with the glazing types and location of blinds (Table 10).

It is generally true that GA is superior to the heuristic approach, not only due to the difference in computational capability between the human brain and machine computing, but also due to the characteristics of human brain activity. Heuristics with anchoring and adjustment are adopted in many situations where people estimate a solution [26]. It involves starting from a readily available estimate (anchor) [27], and shifting either up or down to reach an answer that seems plausible [26]. In this estimation process, people tend to shift not so far enough away from the anchor $[27,28]$. Hence, the anchor contaminates the estimate, even if the anchor is clearly irrelevant. Even when the anchor is obviously extreme or random, it can still contaminate estimates [29]. These kinds of heuristics (anchoring and adjustment) were observed in the optimization process of Case \#1. The insulation 
thicknesses of building envelopes in Case \#1, determined by experts, are not far from those of the original design (Case \#0). The experts considered a variety of insulation thicknesses, but most of the design alternatives are not very different from Case \#0. Consequently, the insulation thicknesses of building envelopes in Case \#1 are determined to be the same as those of Case \#0. In other words, the heuristic approach is limited by the aforementioned anchoring and adjustment, while GA can search a wider solution space.

Case \#3 was achieved from the less constrained search space, and it could save $9 \%$ of the total energy of Case \#2 (Table 9). Not limited to the change in WWR, other changes were also made to the location of blinds and types of glazing of 12 windows (Table 10). Again, as shown in Table 10, it seems difficult to achieve the optimal design result (Case \#3) with educated guesses, prior knowledge, intuition, etc. In addition, it can be inferred that more energy savings could be realized if the optimization approach is adopted at the earlier stage of the building design.

Please note that this study follows a deterministic mono-objective optimal design approach. If uncertainties are taken into account, e.g. heating and cooling setpoint temperatures, infiltration, and occupant behavior with regard to lights and blinds, an optimal design will be determined based on minimizing the degree of risk $[16,30]$.

Acknowledgments: This work was supported by the Korea Institute of Energy Technology Evaluation and Planning (KETEP) and the Ministry of Trade, Industry \& Energy (MOTIE) of the Republic of Korea (No. 20152020105550).

Author Contributions: Won-Jun Suh and Cheol-Soo Park applied the heuristic and meta-heuristic approaches to the design process of the building and analyzed the results in this paper.

Conflicts of Interest: The authors declare no conflict of interest.

\section{References}

1. Caldas, L.G.; Norford, L.K. A design optimization tool based on a genetic algorithm. Autom. Constr. 2002, 11, 173-184. [CrossRef]

2. Pearl, J. Heuristics: Intelligent Search Strategies for Computer Problem Solving; Addison-Wesley: Reading, MA, USA, 1983.

3. Caldas, L.; Norford, L.K.; Rocha, J. An evolutionary model for sustainable design. Manag. Environ. Qual. Int. J. 2003, 14, 383-397. [CrossRef]

4. Coley, D.A.; Schukat, S. Low-Energy design: Combining computer-based optimisation and human judgment. Build. Environ. 2002, 37, 1241-1247. [CrossRef]

5. Kampf, J.H.; Wetter, M.; Robinson, D. A comparison of global optimization algorithms with standard benchmark functions and real-world applications using EnergyPlus. J. Build. Perform. Simul. 2010, 3, 103-120. [CrossRef]

6. Elbeltagi, E.; Hegazy, T.; Grierson, D. Comparison among five evolutionary-based optimization algorithms. Adv. Eng. Inform. 2005, 19, 43-53. [CrossRef]

7. Hamdy, M.; Nguyen, A.-T.; Hensen, J. A performance comparison of multi-objective optimization algorithms for solving nearly-zero-energy-building design problems. Energy Build. 2016, 121, 57-71. [CrossRef]

8. Nguyen, A.-T.; Reiter, S.; Rigo, P. A review on simulation-based optimization methods applied to building performance analysis. Appl. Energy 2014, 113, 1043-1058. [CrossRef]

9. Banos, R.; Manzano-Agugliaro, F.; Montoya, F.G.; Gil, C.; Alcayde, A.; Gomez, J. Optimization methods applied to renewable and sustainable energy: A review. Renew. Sustain. Energy Rev. 2011, 15, 1753-1766. [CrossRef]

10. Oh, S.M.; Kim, Y.J.; Park, C.S.; Kim, I.H. Process-Driven BIM-based optimal design using integration of EnergyPlus, genetic algorithm, and Pareto optimality. In Proceedings of the 12th Conference of International Building Performance Simulation Association, Sydney, Australia, 14-16 November 2011; pp. 894-901.

11. Asadi, E.; de Silva, M.G.; Antunes, C.H.; Dias, L. A multi-objective optimization model for building retrofit strategies using TRNSYS simulations, GenOpt and MATLAB. Build. Environ. 2012, 56, 370-378. [CrossRef]

12. Ihm, P.; Krarti, M. Design optimization of energy efficient residential buildings in Tunisia. Build. Environ. 2012, 58, 81-90. [CrossRef] 
13. Yao, J. Energy optimization of building design for different housing units in apartment buildings. Appl. Energy 2012, 94, 330-337. [CrossRef]

14. Evins, R. A review of computational optimization methods applied to sustainable building design. Renew. Sustain. Energy Rev. 2013, 22, 230-245. [CrossRef]

15. Attia, S.; Hamdy, M.; O’Brien, W.; Carlucci, S. Computational optimization for zero energy buildings design: Interviews results with twenty eight international experts. In Proceedings of the 13th Conference of International Building Performance Simulation Association, Chambery, France, 26-28 August 2013.

16. Kim, Y.J.; Park, C.S. Multi-Criterion stochastic optimal selection of a double glazing system. Build. Simul. 2017, 10, 1-9. [CrossRef]

17. Mitchell, M. An Introduction to Genetic Algorithm; The MIT Press: Cambridge, UK, 1997.

18. Ooka, R.; Komamura, K. Optimal design method for building energy systems using genetic algorithms. Build. Environ. 2009, 44, 1538-1544. [CrossRef]

19. Grefenstette, J. Optimization of control parameters for genetic algorithms. IEEE Trans. Syst. Man Cybern. 1986, 16, 122-128. [CrossRef]

20. Back, T. Evolutionary Algorithms in Theory and Practice; Oxford University Press: Oxford, UK, 1996.

21. Back, T.; Fogel, D.B.; Michalewicz, Z. Evolutionary Computation 2: Advanced Algorithms and Operators (Evolutionary Computation); IOP Publishing Ltd.: Bristol, UK, 1996.

22. Deb, K.D. Multi-Objective Optimization Using Evolutionary Algorithms; John Wiley \& Sons Inc.: New York, NY, USA, 2001.

23. Wright, J.; Alajmi, A. The robustness of genetic algorithms in solving unconstrained building optimization problems. In Proceedings the 9th Conference of International Building Performance Simulation Association, Montreal, QC, Canada, 15-18 August 2005; pp. 1361-1368.

24. Wright, J.; Farmani, R. The simultaneous optimization of building fabric construction, HVAC system size, and the plant control strategy. In Proceedings the 7th Conference of International Building Performance Simulation Association, Rio de Janeiro, Brazil, 13-15 August 2001; pp. 865-872.

25. Palonen, M.; Hasan, A.; Siren, K. A genetic algorithm for optimization of building envelope and HVAC system parameters. In Proceedings the 11th Conference of International Building Performance Simulation Association, Glasgow, Scotland, 27-30 July 2009; pp. 159-166.

26. Baron, J. Thinking and Deciding, 3rd ed.; Cambridge University Press: New York, NY, USA, 2000.

27. Tversky, A.; Kahneman, D. Judgments under Uncertainty: Heuristics and Biases. Science 1974, 185, $1124-1131$. [CrossRef] [PubMed]

28. Keohler, D.J.; Harvey, N. Blackwell Handbook of Judgment and Decision Making; Wiley-Blackwell: Oxford, UK, 2004.

29. Mussweller, T.; Englich, B.; Strack, F. Cognitive Illusions: A Handbook on Fallacies and Biases in Thinking, Judgment and Memory; Psychology Press: New York, NY, USA, 2004; pp. 183-200.

30. Kim, Y.J.; Ahn, K.U.; Park, C.S. Decision Making of HVAC System using Bayesian Markov Chain Monte Carlo method. Energy Build. 2014, 72, 112-121. [CrossRef]

(C) 2017 by the authors. Licensee MDPI, Basel, Switzerland. This article is an open access article distributed under the terms and conditions of the Creative Commons Attribution (CC BY) license (http://creativecommons.org/licenses/by/4.0/). 